\title{
DIGRESSION FROM THE CONVENTIONAL, THE MANY FACES OF AMELOBLASTOMA AND ITS MALIGNANT COUNTERPART- AN INSTITUTIONAL STUDY
}

\author{
D. Gowri Manohari ${ }^{1}$, R. Narmadha², A. P. Rajesh Natraj ${ }^{3}$, J. Bharathi Vidhya Jayanthi ${ }^{4}$
}

1Postgraduate Student, Institute of Pathology, Madras Medical College, Chennai, Tamilnadu, India.

${ }^{2}$ Associate Professor, Department of Pathology, Government Thoothukudi Medical College, Tamilnadu, India.

${ }^{3}$ Assistant Professor, Institute of Pathology, Madras Medical College, Chennai, Tamilnadu, India.

${ }^{4}$ Director, Institute of Pathology, Madras Medical College, Chennai, Tamilnadu, India.

\begin{abstract}
\section{BACKGROUND}

Ameloblastoma is a tumour of odontogenic epithelial origin with multiple histologic variants mainly affecting the bones of maxillomandibular complex. It is a slow growing tumour with an invasive behaviour and with a high rate of recurrence. Ameloblastic carcinoma is a rare odontogenic tumour that combines the histological features of Ameloblastoma with cytological atypia, with or without metastases. We wanted to analyse and categorize the variants of Ameloblastoma among oral and nasal cavity tumours. This study analyses the age group affected, incidence in males and females, commonest site of occurrence and clinical presentation. This study also analyses other benign and malignant neoplasms presenting in oral and nasal cavity.
\end{abstract}

\section{METHODS}

This study was conducted at Institute of Pathology, Madras Medical College, Chennai for a period of three months from January 2018 to March 2018. 76 cases of oral and nasal cavity tumours were studied and categorized. Samples were received in $10 \%$ neutral buffered formalin and processed as per protocols. Immunohistochemistry was done when required. The tumours were analysed and categorized based on histomorphological and immunohistochemical features. The different immunohistochemical stains used in this study are CK14, CK19, CK 5/6 p63, EMA and CEA.

\section{RESULTS}

Out of 76 cases of benign and malignant neoplasms, the incidence of Ameloblastoma is 7.8\% (6 cases) and one case was Ameloblastic carcinoma with an incidence of $1.3 \%$, though squamous cell carcinomas constitutes $60 \%$ of all malignancies. The commonest age group of presentation of Ameloblastoma is third and fourth decade with female predilection. The commonest site in present study is maxilla.

\section{CONCLUSIONS}

Ameloblastomas are the most common tumours of odontogenic epithelium, they show wide range of variations and sometimes they behave in a malignant fashion. The diagnosis of odontogenic tumours can be challenging largely due to its rarity. In most cases, careful attention to the morphology, clinical and radiological features will allow a diagnosis to be made. In some cases, immunohistochemical analysis of the tumour is useful, especially in an Ameloblastic carcinoma. This study emphasizes the usefulness of immunohistochemistry in difficult cases.

\section{KEY WORDS}

Odontogenic Epithelium, Ameloblastoma, Ameloblastic Carcinoma, EMA, CEA, p63

HOW TO CITE THIS ARTICLE: Manohari GD, Narmadha R, Natraj APR, et al. Digression from the conventional, the many faces of ameloblastoma and its malignant counterpart- an institutional study. J. Evolution Med. Dent. Sci. 2019;8(24):1940-1944, DOI: $10.14260 /$ jemds/2019/426

\section{BACKGROUND}

Ameloblastoma was first identified by Cusack in 1827, when an odontogenic tumour was described with multiple cords and interconnected cell laminas, of epithelial origin, homologous with the dentogingival lamina of onset during odontogenesis. It may originate from rests of the enamel organ, epithelial cell rests of Malassez or sheet of Hertwig, from the basal cells of the

'Financial or Other Competing Interest': None.

Submission 30-04-2018, Peer Review 04-06-2019,

Acceptance 10-06-2019, Published 17-06-2019.

Corresponding Author:

Dr. R. Narmadha,

Associate Professor

Department of Pathology,

Government Thoothukudi Medical College,

Thoothukudi, Chennai, Tamilnadu, India.

E-mail: narmiram2@gmail.com

DOI: $10.14260 /$ jemds $/ 2019 / 426$ oral mucosa, Epithelial boundary of an odontogenic cyst (dentigerous cyst), Heterotopic epithelium from other parts of the body. ${ }^{1}$ The World health organization (WHO) 2017 defines Ameloblastoma as benign epithelial odontogenic tumour of the jaw bone. Benign Ameloblastoma are the most common odontogenic tumour which can be locally invasive and aggressive, and they represent the odontogenic tumour of higher clinical significance. ${ }^{2,3}$

\section{Clinical Features}

Commonest age group affected is second to sixth decade ${ }^{3}$ The most common presentation is painless swelling of mandible or maxilla, ${ }^{4,5}$ affecting females more than males. ${ }^{6}$ It causes facial disfigurement in advanced cases. ${ }^{7}$ The lesions are larger and occur earlier in females. ${ }^{8}$ In contrary, some studies show higher incidence in males and maxilla as the commonest site. ${ }^{9}$ 


\section{Radiological Features}

They are detected incidentally as a lytic lesion with scalloped margins. The classic soap bubble appearance is seen in most of the multicystic variants. Sometimes x-rays lack sensitivity or specificity whereas CT is the most useful diagnostic modality, typically demonstrating well defined radiolucent expansile lesions. It also enhances the degree of cortical destruction and soft tissue extension. MRI provides most useful information of soft tissue extension particularly in maxillary tumours and desmoplastic variant. Though there are many imaging modalities, biopsy is the gold standard for diagnosis.

\section{Histological Features}

The characteristic histological features of Ameloblastoma are presence of loosely arranged Stellate cells showing a resemblance to the reticulum of the tooth germ, tumour cells are arranged with peripheral palisading and nuclei are directed away from the basement membrane with reversal of polarity.

\section{Morphological Variants}

Ameloblastoma is categorised into conventional solid or multicystic and rare uni cystic variants. Among the solid or multicystic ameloblastoma the different morphological variants are-

1. Follicular Ameloblastoma- Characterized by islands of epithelium with peripheral palisading of elongated columnar cells with reversed polarity, in that the nuclei are oriented away from the basement membrane. These cells resemble the pre-ameloblasts of normal tooth development. Centrally the islands contain loosely arranged stellate reticulum.

2. Acanthomatous Ameloblastoma- Show evidence of squamous metaplasia within the tumour follicles, the stellate reticulum like appearance is lost, and keratinization may be seen. A minority of tumours show areas of eosinophilic granular cells.

3. Plexiform Ameloblastoma- Consists of strands and cords of epithelium, often interconnecting. Columnar ameloblastlike cells are seen at the periphery, but stellate reticulum areas may be difficult to be found.

4. Desmoplastic Ameloblastoma- Show extensive stromal desmoplasia $^{10}$ characterized by densely collagenous fibrous tissue and, occasionally, bone formation. The epithelial component may be reduced to thin anastomosing strands, although typical follicles with peripherally palisaded cells are found.

Other uncommon variants are basaloid, papilliferous and some tumours may show clear cells. Cytologically the cells are bland and mitotic activity is difficult to identify. If mitotic activity is high, possibility of malignant ameloblastoma should be considered. Uni cystic Ameloblastoma are rare and present as unilocular cysts and they are common in younger age group. They are treated by enucleation. Peripheral ameloblastoma may arise from the oral epithelium of the gingiva or alveolus rather than within bone. Peripheral Ameloblastoma appear less aggressive than intraosseous lesions.

\begin{tabular}{|c|c|}
\hline $\begin{array}{c}\text { Benign Tumours in Oral and Nasal } \\
\text { Cavity }\end{array}$ & $\begin{array}{c}\text { Number of Cases in Present } \\
\text { Study }\end{array}$ \\
\hline Ameloblastoma & 5 \\
\hline $\begin{array}{c}\text { Dentigerous cyst with focal } \\
\text { ameloblastic transformation }\end{array}$ & 1 \\
\hline Inverted papilloma & 4 \\
\hline Juvenile nasal angiofibroma & 3 \\
\hline Lobular capillary haemangioma & 3 \\
\hline myoepithelioma & 1 \\
\hline Cemento-ossifying fibroma & 1 \\
\hline Angiomyxoma & 1 \\
\hline
\end{tabular}

Table 1. Incidence of Ameloblastoma and Other Benign Tumours in Oral and Nasal Cavities

\begin{tabular}{|c|c|}
\hline $\begin{array}{c}\text { Malignant Tumours in Oral and Nasal } \\
\text { Cavity }\end{array}$ & $\begin{array}{l}\text { Number of Cases in Present } \\
\text { Study }\end{array}$ \\
\hline Ameloblastic carcinoma & 1 \\
\hline Squamous cell carcinomas & 45 \\
\hline Non-Hodgkin's lymphoma & 4 \\
\hline Angiosarcoma & 2 \\
\hline Osteosarcoma & 1 \\
\hline Poorly differentiated carcinoma & 3 \\
\hline Sarcomatoid carcinoma & 1 \\
\hline \multicolumn{2}{|c|}{$\begin{array}{c}\text { Table 2. Incidence of Ameloblastic Carcinomas and other } \\
\text { Malignant Tumours in Oral and Nasal Cavity }\end{array}$} \\
\hline
\end{tabular}
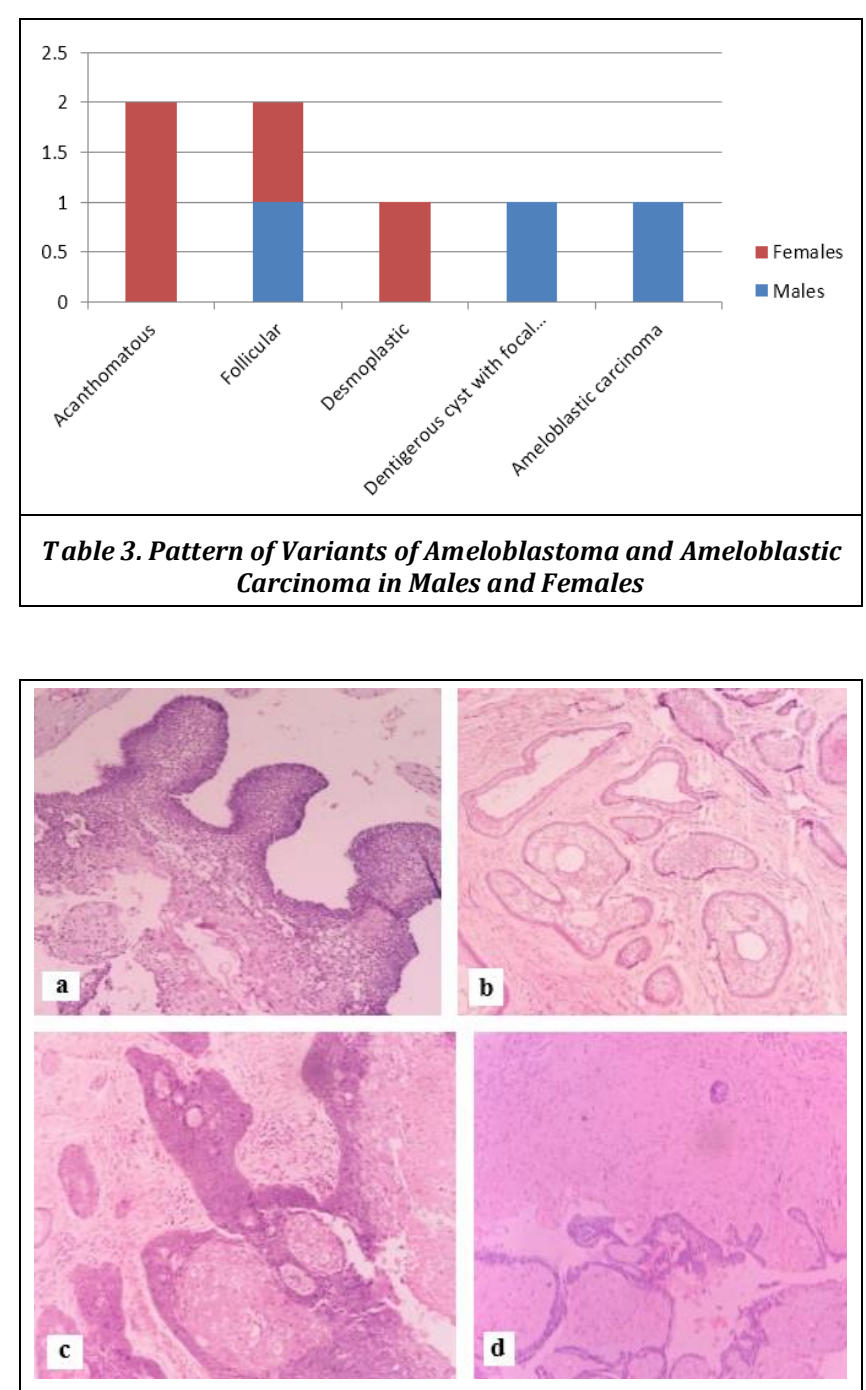

Figure 1. Photomicrograph Showing Histomorphological Pictures of a) Ameloblastic Transformation in a Dentigerous Cyst in 100X b) Follicular Ameloblastoma in 100X c) Acanthomatous

Ameloblastoma in $100 \mathrm{X}$ d) Desmoplastic Ameloblastoma in $100 \mathrm{X}$ 


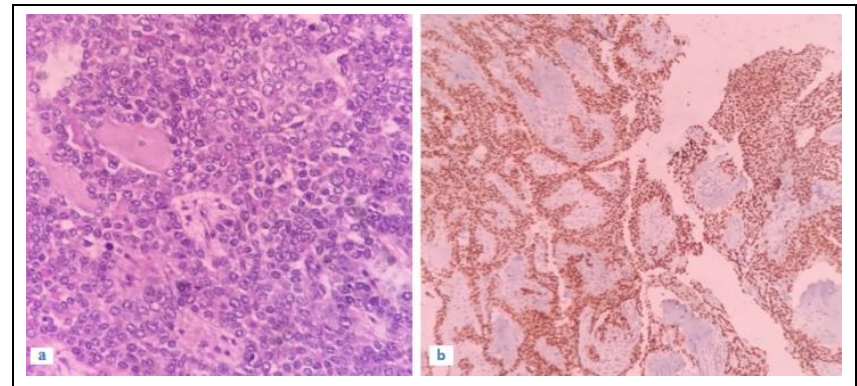

Figure 2. Photomicrograph of a) Histomorphological Features of Ameloblastic Carcinoma in 400 X (Pleomorphic Vesicular Nuclei and Mitotic Figures) b) Immunohistochemistry Shows Increased p63 Expression in $100 \mathrm{X}$.

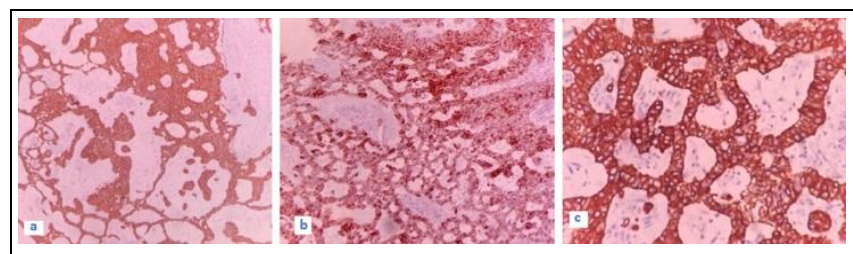

Figure 3. Photomicrograph Showing Immunohistochemistry Pictures of Ameloblastic Carcinoma. a) Strong Positivity for CK14 in $40 X$ b) Strong Positivity for CK19 in $100 \mathrm{X}$ c) Strong Positivity for CK5/6 in $400 X$

\section{Metastatic Ameloblastoma}

Metastatic ameloblastomas typically demonstrate well differentiated benign histology similar to solid/multicystic type at the primary site, but additional foci of benign histology are identified in location distant from the primary and considered to be metastasis.11,12 The histological features of primary and metastatic lesions show similar histomorphological features. They frequently metastasize to the lung, followed by bone, liver and brain. ${ }^{13,14}$ Regional neck metastasis is common in cases of malignant transformation of primary Ameloblastoma.

\section{Ameloblastic Carcinoma}

Ameloblastic carcinomas are rare odontogenic tumour accounting for 1.5 to $2 \%$ of all odontogenic tumours. Ameloblastic carcinoma exhibits malignant histological features such as cytological atypia, increased or abnormal mitoses is the most aggressive of subtypes and can be further divided into two subtypes: primary and secondary. Primary ameloblastic carcinoma arises de novo, while secondary Ameloblastic carcinomas are a result of malignant transformation of a previously diagnosed benign ameloblastoma. ${ }^{15}$ They are common in men than women. Several studies suggest that Ameloblastic carcinoma can be identified by the presence of following features like higher proliferative mitotic index, higher proliferating cell nuclear antigen expression of ki67,16 nuclear atypia such as nuclear pleomorphism and basilar hyperplasia, hyperchromatic nuclei, perineural or perivascular invasion.

Immunohistochemistry plays a vital role in the diagnosis of Ameloblastoma, whenever the diagnosis is challenging. Development of tooth is a highly complex process with morphological changes in each phase of development. The odontogenic epithelium expresses cytokeratins such CK 14, 19 and CK 5/6. CK 14 is expressed by odontogenic epithelium in all stages of tooth development in peripheral cells whereas CK 19 is expressed only in later stages but by all cells. ${ }^{17}$ p63 often expressed in normal epithelium and overexpressed in carcinomas including Squamous cell carcinomas and also in
Ameloblastic carcinomas suggesting that p63 may have a role in tumourigenesis. ${ }^{18}$

In this retrospective study all the tumours of the oral and nasal cavity were studied, among which 7 cases of ameloblastomas analysed and categorized based on the incidence, age and sex distribution, anatomical location, histomorphological and immunohistochemical features.

\section{METHODS}

The observational study was conducted at the Institute of Pathology, Madras Medical College, Chennai for a period of three months from January 2018 to March 2018. All the benign and malignant tumours of oral and nasal cavity were considered, with inflammatory, granulomatous and traumatic lesions were excluded in this study. 76 cases of benign and malignant tumours of oral and nasal cavity were reported during study period. Sample size was taken based on the convenience of the study. Specimens received in the Institute of Pathology, were fixed in $10 \%$ neutral buffered formalin and processed as per guidelines. The clinical features, imaging and preoperative findings were analysed. Based on the histomorphological studies, the tumours were analysed and categorised. Immunohistochemistry was done whenever required to confirm the diagnosis.

\section{Statistical Methods}

The statistical package for social science $\{$ SPSS $\}$ version 20 will be used for data analysis. Mean, median, and SD are used to describe quantitative data. Qualitative data are summarized using frequency and percentage.

\section{RESULTS}

In present study the incidence of Ameloblastoma is 7.8\% (6/76) and Ameloblastic carcinoma is $1.3 \%(1 / 76)$ of the total of 76 cases of benign and malignant tumours. Among them, 19 were benign and 57 were malignant

The commonest age group affected by Ameloblastoma is third to fourth decade however the age range was found between 20 to 60 year. The incidence of Ameloblastomas were more in females $4 / 6(66 \%)$ cases and $2 / 6(23 \%)$ cases in males. Whereas Ameloblastic carcinoma has occured in male patient in present study (1/7).

Of the benign cases, there were 4 cases of Ameloblastoma with 1 case of dentigerous cyst with focal Ameloblastic transformation, 4 cases of Inverted papilloma, 3 cases of Lobular haemangioma, 3 cases of Juvenile nasopharyngeal angiofibroma and one case each of Myoepithelioma, Angiomyxoma and Cemento ossifying fibroma.(Table 1). Among the malignant tumours there were 1 case of Ameloblastic carcinoma, 45 cases of Squamous cell carcinoma, 4 cases of NonHodgkin lymphoma, 3 cases of poorly differentiated carcinoma and 1 case of Sarcomatoid carcinoma (Table 2)

Distribution based on site: Among the total of 76 cases of oral and nasal cavity tumours, 49 cases occurred in oral cavity and 27 cases in nasal cavity. Out of 49 oral cavity tumours 4 were benign including one case of dentigerous cyst with focal ameloblastic transformation, 2 cases of lobular capillary haemangioma and 2 cases of ameloblastomas and 44 were malignant, including 42 cases of squamous cell carcinomas and one case each of angiosarcoma and Non-Hodgkin lymphoma.

Of 27 nasal cavity tumours, 15 were benign including 4 cases of Ameloblastomas, 4 cases of Inverted papilloma, 3 cases of 
Juvenile nasal angiofibroma and one case of Myoepithelioma, Cemento ossifying fibroma, Angiomyxoma, Lobular capillary haemangioma. Remaining 12 cases were malignant comprising of 1 case of Ameloblastic carcinoma, 3 cases of Squamous cell carcinoma, 3 cases of Non Hodgkin lymphoma, 2 cases of Osteosarcoma, 1 case of Sarcomatoid carcinoma, 1 case of Myeloid sarcoma and 1 case of Poorly differentiated carcinoma making the incidence of Ameloblastic carcinoma in our study is $1.3 \%$.

\section{Distribution Based on Histological Variants}

Among the 6 Ameloblastoma cases, there were 2 cases each of Acanthomatous and Follicular Ameloblastomas and 1 case of Desmoplastic Ameloblastoma. 1 case of Dentigerous cyst with Ameloblastic transformation, 1 case of desmoplastic variant and one was dentigerous cyst with focal ameloblastic transformation. Among the malignant tumours there was one case of Ameloblastic carcinoma. (Table 3). Figure 1 shows the histomorphological features of various Ameloblastomas in present study.

The commonest site of Ameloblastoma including Ameloblastic carcinoma in this study is maxilla $5 / 7$ cases. One case was dentigerous cyst with focal ameloblastic transformation in a 20-year female presented as dental cyst, three cases of Ameloblastoma presented as mass in maxillary sinus region. Other cases presented as mandibular swelling.

A 40-year-old male presented wih clinical diagnosis of carcinoma left maxilla and maxillectomy was done. Grossly it was a proliferative and nodular growth measuring $7 \times 5.5 \times 5 \mathrm{~cm}$. Cut surface of the growth was grey white, friable with focal haemorrhagic and cystic spaces. Microscopically the neoplasm exhibited the features of Ameloblastoma with areas of necrosis and desmoplasia. The mitotic activity is 3-4/ high power field. (Figure 2 and figure 3 depicts the histomorphological and immunohistochemical features of Ameloblastic carcinoma)

\section{DISCUSSION}

Ameloblastoma is the most common benign epithelial odontogenic tumours of the jaw bone ${ }^{2}$ and defined by WHO as a benign progressively growing neoplasm characterized by expansion and a tendency for local recurrence if not adequately removed. Histopathologically, they resemble normal odontogenic epithelium and ectomesemchyme. They arise from the epithelial remnants of tooth development, from dentigerous cysts and heterotopic epithelium from other parts of the body. ${ }^{1}$

In present study the incidence of Ameloblastoma is $7.8 \%$ (6/76) which is closer to a study done by Ramachandra et al, the incidence rate of odontogenic tumours in their study is $5.7 \%$. The incidence of Ameloblastomic carcinoma is $1.3 \%(1 / 76) .(2,1)$ In our study Ameloblastoma occurred most commonly in females similar to studies done by Ramachandra et $\mathrm{al}^{3}$ and Fernandez et al 45 out of 6 ameloblastoma cases in females and 1 case in male. The commonest age group affected is third to fourth decade though the age range was 20-60 years, the youngest age of ameloblastomas in present study is 20 years who presented with dentigerous cyst with focal ameloblastic transformation and oldest age is 61 years, 5,8 the age range is second decade to sixth decade which is similar to a study done by Ahmed Qannam.19

The commonest site of ameloblastoma including Ameloblastic carcinoma in our study is maxilla (5/7 cases) and 2 cases in mandible presented as oral cavity mass, which is contradictory to other studies. 1,4,6,7 In most of the studies the commonest site is mandible. However, in a study done by Ochensius et al, the commonest site of odontogenic tumours is maxilla. ${ }^{9}$ The commonest location of Desmoplastic Ameloblastoma has a predilection for the anterior region of the jaws especially the maxilla as in a study done by Philipsen et al which is similar to our study. 10

Malignant Ameloblastoma metastasizes inspite of benign histological appearance.11,12 They can metastasise to lymph nodes locally or distant organs such as lungs, brain and skin ${ }^{11,}$ 12. Unlike Ameloblastoma, Ameloblastic carcinoma are more aggressive with perforation of the cortical plate, extension into surrounding soft tissue, lower lip paraesthesia, and persistent pain. In present study we had one case of Ameloblastic carcinoma, (1/7) with the incidence of $1.3 \%$ which parallels with other studies also13,14 however the most common malignant tumour was Squamous cell carcinoma. In a study done by Alexandra Rizzitelli et al majority of Ameloblastic carcinomas has occurred in males, in present study one case of Ameloblastic carcinoma in a 46-year-old male patient. ${ }^{15}$

Immunohistochemistry was done to confirm the diagnosis with markers such as CK 14, 19, 5/6, EMA, CEA and p63. Among them CK14, CK19 and CK5/6 exhibited diffuse strong positivity. CK 14 is expressed by diverse components during all stages of tooth development, including the dental lamina, the inner enamel epithelium and in almost all cells of the enamel organ, while CK 19 is mainly positive in the later stages of development during terminal differentiation of Ameloblastomas as seen in study done by Marisol Martinez et al, Keith D. Hunter et al ${ }^{16,17}$ while EMA, CEA were negative. p63 exhibited diffuse strong nuclear positivity in tumour cells. p63 is often expressed in normal epithelium and is often overexpressed in carcinomas as cited in a study done by Atarbashi et al. 18

\section{Prognosis}

Prognosis depends upon the age of the patient, tumour size, extent of disease, location of tumour. Maxillary ameloblastoma are very aggressive since thin cortical bone of maxilla serves as a weaker barrier. Recurrence rates depends upon the adequacy of the surgical margins and extension into vital organs. Ameloblastoma if untreated can grow to a very large size and pose an airway risk and metabolic abnormalities. Furthermore, numerous recurrent lesions and metastasis, usually to cervical lungs, bone, liver, and brain have been reported.

\section{CONCLUSIONS}

Ameloblastoma is a rare odontogenic tumour that is slow growing, with a propensity of locoregional invasion and risk of recurrence. Ameloblastoma present with various histological types and sometimes impart diagnostic difficulties and this is where immunohistochemistry come into play.

From first being described by Cusack and to the recent immunohistochemical markers and molecular genetics our understanding of Ameloblastoma has greatly improved which will pose no difficulty in the diagnosis of Ameloblastomas and their treatment.

\section{REFERENCES}

[1] Lesot $\mathrm{H}$, Brook AH. Epithelial histogenesis during tooth development. Archives of Oral Biology 2009;54 Suppl 1:S25-S33. 
[2] Buchner A, Merrell PW, Carpenter WM. Relative frequency of central odontogenic tumours: a study of 1 , 088 cases from Northern California and comparison to studies from other parts of the world. J Oral Maxillofac Surg 2006;64(9):1343-52.

[3] Ramachandra S, Shekar PC, Prasad S, et al. Prevalence of odontogenic cysts and tumours: a retrospective clinicopathological study of 204 cases. SRM Journal of Research in Dental Sciences 2014;5(3):170-3.

[4] Fernandes AM, Duarte EC, Pimenta FJ, et al. Odontogenic tumours: a study of 340 cases in a Brazilian population. Journal of Oral Pathology and Medicine 2005;34(10):583-7.

[5] Olaitan PB, Jiburum BC, Onuigbo WIB. Clinicopathological features of jaw tumours. Indian Journal of Medical \& Paediatric Oncology 2005;26(4):127.

[6] Jing W, Xuan M, Lin Y, et al. Odontogenic tumours: a retrospective study of 1642 cases in a Chinese population. International Journal of Oral and Maxillofacial Surgery 2007;36(1):20-5.

[7] França LJ, Curioni OA, Paiva DL, et al. Ameloblastoma demographic, clinical and treatment study - analysis of 40 cases. Brazilian Journal of Otorhinolaryngology 2012;78(3):38-41.

[8] Reichart PA, Philipsen HP, Sonner S. Ameloblastoma: biological profile of 3677 cases. European Journal of Cancer Part B: Oral Oncology 1995;31B(2):86-99.

[9] Ochenius G, Ortega A, Godoy L, et al. Odontogenic tumours in Chile: a study of 362 cases. J Oral Pathol Med 2002;31(7):415-20.

[10] Philipsen HP, Reicharl PA, Takata T. Desmoplastic ameloblastoma (including "hybrid" lesion of ameloblastoma). Biological profile based on 100 cases from the literature and own files. Oral Oncol 2001;37(5):455-60.

[11] Clay R. Ameloblastoma metastatic to the lung reply. Annals of Plastic Surgery 1989;23(6):560.

[12] Bi R, Shen L, Zhu X, et al. Malignant ameloblastoma (metastatic ameloblastoma) in the lung: 3 cases of misdiagnosis as primary lung tumour with a unique growth pattern. Diagnostic Pathology 2015;10(1):123.

[13] Loyola AM, Cardoso SV, de Faria PR, et al. Ameloblastic carcinoma: a Brazilian collaborative study of 17 cases. Histopathology 2016;69(4):687-701.

[14] Braimah RO, Uguru C, Ndukwe KC. Ameloblastic carcinoma of the jaws: Review of the literature. Journal of Dental and Allied Sciences 2017;6(2):70-3.

[15] Rizzitelli A, Smoll NR, Chae MP, et al. Incidence and overall survival of malignant ameloblastoma. PLoS One 2015;10(2): e0117789.

[16] Martinez-Martinez M, Mosqueda-Taylor A, Carlos-Bregni $\mathrm{R}$, et al. Comparative histological and immunehistochemical study of ameloblastomas and ameloblastic carcinomas. Medicina Oral Patología Oral y Cirugia Bucal 2017;22(3):e324-e32.

[17] Hunter KD, Speight PM. The diagnostic usefulness of immunohistochemistry for odontogenic lesions. Head and Neck Pathology 2014;8(4):392-9.

[18] Moghadam AS, Moghadam AF, Mokhtari S, et al. Immunohistochemical analysis of p63 expression in odontogenic lesions. Article ID 624176, Biomed Research International 2013;2013:1-4.

[19] Qannam A. Ameloblastoma: analysis of 76 cases from a university-based biopsy service in Saudi Arabia. Pakistan Oral \& Dental Journal 2016;36(2):210-13. 